\title{
Boron segregation in a (Fe, V, B) TiAl based alloy
}

\author{
B.J. INKSON, C.B. BOOTHROYD and C.J. HUMPHREYS
}

Department of Materials Science and Metallurgy, Cambridge University, Pembroke St., Cambridge CB2 $3 Q Z$, England

\begin{abstract}
Primary boron containing dispersoids grown from the melt in a Ti-45.5at.\%Al-1.6at.\%Fe1.1at.\%V-0.7at.\%B alloy, and then annealed at $1473 \mathrm{~K}$, have been investigated using optical microscopy, conventional transmission electron microscopy (CTEM) and analytical electron microscopy. The dispersoid morphology is in the form of high aspect ratio plates, hundreds of microns across and cross-sectional widths of just a few hundred nanometers, rather than a blocky or equiaxed morphology. These dispersoids are not monocrystalline, but have a layered structure parallel to the plane of the plates. The dispersoids are distributed with random orientations throughout the matrix and delineate the edges of lamellar domains, formed by the solid state transformation $\alpha \rightarrow \gamma+\alpha_{2}+\beta$. Microchemical analysis by windowless energy dispersive $\mathrm{x}$-ray analysis (EDX) and serial electron energy loss spectroscopy (EELS) show that the chemical structure of these zones is in fact a mixture of interleaved phases, rather than a single faulted boride crystal. Boron mapping across the zones edge on to the plates and quantitative EDX reveals boride plates down to a few $\mathrm{nm}$ wide have formed interleaved with ordered $\beta$-phase ( $\mathrm{B} 2 \mathrm{CsCl}$ structure). It is concluded that primary borides and $\beta$-phase simultaneously nucleate within the melt, and the $\beta$-phase is stabilized to room temperature by $\mathrm{Fe}$ and $V$ segregation. Hence the borides can act as grain refiners by providing nucleation sites for $\beta$-phase at high temperatures.
\end{abstract}

\section{INTRODUCTION}

TiAl $(\gamma)$ and Ti3Al alloys $\left(\alpha_{2}\right)$ are currently under development as future aerospace alloys, having low density, good high temperature strength and oxidation resistance. It is well established that including even $<1$ at.\%B in two phase $\gamma / \alpha_{2}$ alloys can produce a dispersion of boride particles throughout the microstructure[1-4]. The impact of these reinforcements on various alloy properties, such as modulus and high temperature creep strength, depends on the particulate morphology and dispersion throughout the matrix. These boride particles have been shown to refine grain size[4,5], possibly by providing additional nucleation sites at high temperatures in the melt for the primary TiAl phases $\beta$ and $\alpha$, and should improve the high temperature creep properties of the alloys.

In this study we consider the effect of the addition of $\mathrm{B}$ to a Ti-Al-Fe-V system, which Nakagawa $e t$ al [6] have shown produces TiAl based alloys of good castability for turbine component manufacture. Within this alloy it has been established that Fe and V stabilize the $\beta$-phase [7] within the bulk microstructure, and the morphology of the boride particles is now investigated.

\section{EXPERIMENTAL}

The alloy used for this work had composition Ti-45.5at\%Al-1.6at\%Fe-1.1at\%V-0.7at\%B. It was annealed at $1473 \mathrm{~K}$ for three hours then furnace cooled. Optical specimens were etched using $9 \%$ HF (48\%) 91\% $\mathrm{HNO}_{3}$. Transmission electron microscopy specimens were electropolished using $6 \%$ perchloric acid : $34 \%$ butan-1-ol : $60 \%$ methanol at $240 \mathrm{~K}$ [8]. Characterization was carried out by optical microscopy, conventional transmission electron microscopy (CTEM), energy dispersive X-ray analysis (EDX) and electron energy loss spectroscopy (EELS). The microscopes used for these investigations were a Philips CM30 300kV TEM, and a VG HB501 100kV STEM. 


\section{OPTICAL MICROSCOPY}

The optical microstructure of this alloy, as shown in Fig. 1, consists of domains with a lamellar structure and single phase grains several hundred microns across. There are dispersoids distributed throughout the microstructure. In cross-section the dispersoid morphology is of the form of narrow fibrous ribbons, hundreds of microns long with a very high aspect ratio, rather than a blocky or equiaxed morphology. Hence in three dimensions the dispersoid morphology is of very thin flakes, gently curved. The flakes are distributed with random orientations throughout the matrix and both cut across lamellar domains, and delineate domain boundaries shown in Fig. 1.

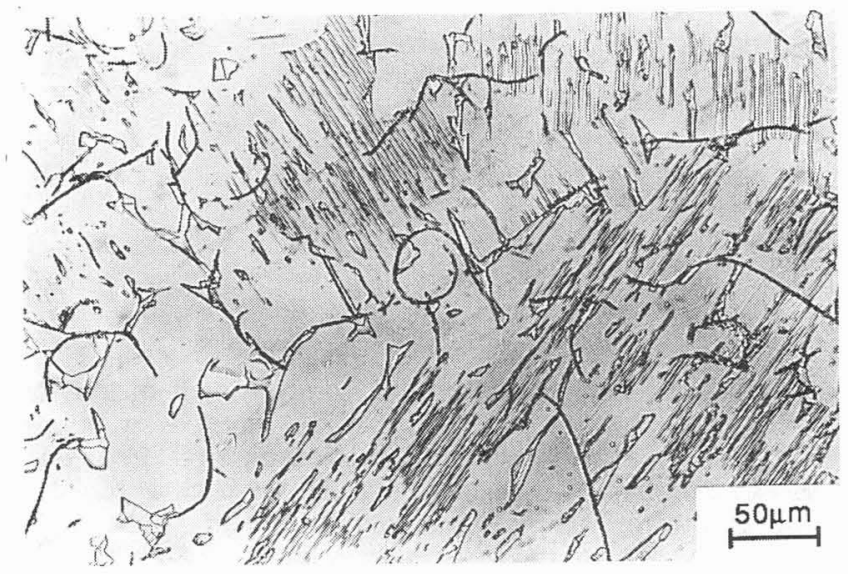

Fig. 1. Optical microstructure of Ti-45.5at\%Al-1.6at\%Fe-1.1at\%V-0.7at\%B alloy exhibiting randomly orientated dispersoids delineating lamellar domain boundaries.

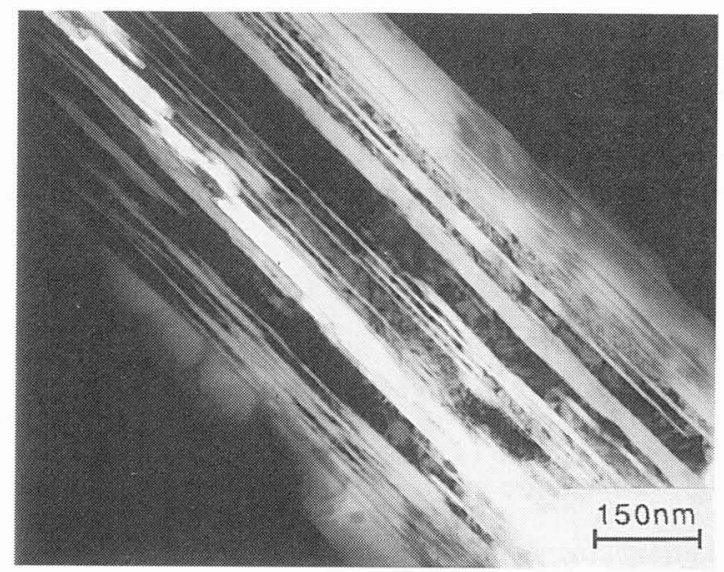

Fig. 2. TEM bright field micrograph of a dispersoid illustrating the finely layered microstructure parallel to the plane of the flakes.

\section{CTEM MICROSTRUCTURAL OBSERVATIONS}

This alloy contained the ordered intermetallic phases $\gamma$-TiAl, $\alpha_{2}$-Ti3 $\mathrm{Al}$, and $\beta$-Ti hereafter referred to as $\gamma$ and $\alpha_{2}$ and $\beta . \gamma$ has the tetragonal $L 1_{0}$ structure $(a=0.401 \mathrm{~nm}, c=0.407 \mathrm{~nm}), \alpha_{2}$ the hexagonal D0 19 structure $(a=0.578 \mathrm{~nm}, c=0.463 \mathrm{~nm})$, and $\beta$ the ordered cubic $\mathrm{B} 2 \mathrm{CsCl}$ type structure $(a=0.316 \mathrm{~nm})$. The ordered $\beta$-phase occurs due to the presence of $\mathrm{Fe}$ and $\mathrm{V}$, which stabilize the B2 $\mathrm{CsCl}$ structure by segregating to the b.c.c $\mathrm{Al}$ sub-lattice [7].The bulk microstructure of this alloy consists of large primary $\gamma$-grains of the order of $300 \mu \mathrm{m}$ in size and lamellar domains formed by the solid state transformations disordered $\beta$-phase $\rightarrow \alpha \rightarrow \alpha_{2}+\gamma+\beta$ (ordered).

As optically, dispersoids were observed to both cut across lamellar domains, and delineate $\alpha_{2}+$ $\gamma+\beta$ domain boundaries, from which it can be deduced that the dispersoids formed before the solid 
state transformation $\alpha \rightarrow \alpha_{2}+\gamma+\beta$. In cross-section the dispersoids are a mere few hundred nanometers across, although many hundreds of microns long. The dispersoids are not monocrystalline. There is a layering parallel to the major plane of the flakes shown in Fig. 2, and dislocations occur at these layer interfaces. This suggests that the layering is not due to coherent boundaries, but possibly due to different phases. The uneven contrast suggests the wider plates may be strained between the very fine layers. The layers are not continuous along the length of the flake, but stop and start i.e. there are many smaller plates intermeshed to form one large dispersoid. Layering is apparent on the nanometre scale up to the resolution of the transmission electron microscope, so the composition of the interleaving plates was investigated a HB 501 STEM with small probe size.

\section{COMPOSITIONAL ANALYSIS}

Compositional analysis on the dispersoids and bulk phases $\gamma, \beta$ and $\alpha_{2}$ was carried out using a $S T E M$ at $100 \mathrm{kV}$ with probe size of $1-2 \mathrm{~nm}$. Energy dispersive $X$-ray studies produced spot spectra, line scans and X-ray maps. Serial EELS studies were carried out to locate boron. No boron edges were located in EELS spectra taken from the bulk $\gamma, \beta$ and $\alpha_{2}$ grains indicating a concentration of less than a few percent, if any, of boron within these phases. Boron edges were only present in serial EELS spectra taken from the dispersoid zones.

Spot spectra, line scans and X-ray maps were taken from a chosen dispersoid region. In order to analyse any relative composition changes across the dispersoid, $\mathrm{X}$-ray line scans and maps were collected using energy windows on the $A 1 \mathrm{~K}_{\alpha}$ peak, Ti $\mathrm{K}_{\alpha}$ peak, $\mathrm{Fe} \mathrm{K}_{\alpha}$ peak and the $\mathrm{V} \mathrm{K}_{\beta}$ peak, the same windows being used for all analyses. The same procedure was used as outlined elsewhere[7], with the $V K_{\beta}$ peak being used due of the overlap of the $T i K_{\beta}$ and $V K_{\alpha}$ peak producing a very poor signal to noise ratio. To reduce the influence of thickness variations between the various phases, and to obtain relative changes of composition, the counts under each peak of $A l K_{\alpha}, \mathrm{Ti} \mathrm{K}_{\alpha}, \mathrm{Fe} \mathrm{K}_{\alpha}$ and V K were normalized by dividing by the total number of counts for all four energy windows, and the results presented have been nomalized in this way. For the spot spectra background counts were also subtracted. Thus although absolute compositions could not be reliably determined, relative changes between the phases could be investigated.

\subsection{EDX X-ray mapping and line scans}

The distribution of $\mathrm{Al}, \mathrm{Ti}, \mathrm{V}$ and $\mathrm{Fe}$ across the investigated region shown in Fig. 3 was measured with the grains orientated away from a channeling condition. If the dispersoids were simple faulted titanium boride grains then one would expect the EDX maps in these regions to be uniform, however this is clearly not the case. Strong banding is apparent parallel to the plane of the dispersoid flake due to different phases being present. The Al (Fig. 3(a)) and Ti (Fig. 3(b)) are not coincident, with the Ti X-ray signal a maximum when Fe (Fig. 3(d)) and Al X-ray signals are a minimum. The regions of $\mathrm{Al}$ and $\mathrm{Fe}$ deficit were of the order of $10 \mathrm{~nm}$ across in size. The $\mathrm{V}$ signal (Fig. 3(c)) was simply noise. The X-ray line scan of the $A 1 K_{\alpha}$, Ti $K_{\alpha}, V K_{\beta}$ and $F e K_{\alpha}$ energy windows shown in Fig. 4 was taken parallel to the edge of the foil to minimise thickness variations during the scan. Taken perpendicular to the dispersoid banding, it shows similar features to the X-ray maps. To determine the existance of a titanium boride the same region was investigated using EELS.

\subsection{Correlation OF EDX with EELS for structure determination}

Only EELS spot spectra taken from the regions of the $\mathrm{Ti}$ maxima contained boron edges, indicating that the regions between contain less than a few percent of boron. To map out the location of the boron EELS imaging was undertaken. Energy filtered EELS maps were taken in two energy windows before the $188 \mathrm{eV}$ boron edge at $165 \mathrm{eV}$ and $180 \mathrm{eV}$, and one afterwards at $196 \mathrm{eV}$. The slit width was $13 \mathrm{eV}$. The three images were cross-correlated in order to determine any shift caused by drift of the image, and aligned accordingly. By forming a projected background from the first two maps taken before the boron edge, and removing this from the third taken after the boron edge, an image was formed of where the electrons suffering from boron $K$ shell energy loss transistions came from.

Figure 5 is such a boron map determined from energy filtered EELS images taken from the same region of dispersoid as used in the EDX mapping. The boron stripes in this image correspond to the Ti maxima as seen in Fig. 3(c), confirming the existance of a titanium boride. Looking at the scale of these images, the boron is located in plates that are just of the order of $10 \mathrm{~nm}$ across in this case, and are probably even narrower allowing for the edges of the plates not lying edge on to the detector and the resolution of the probe. 

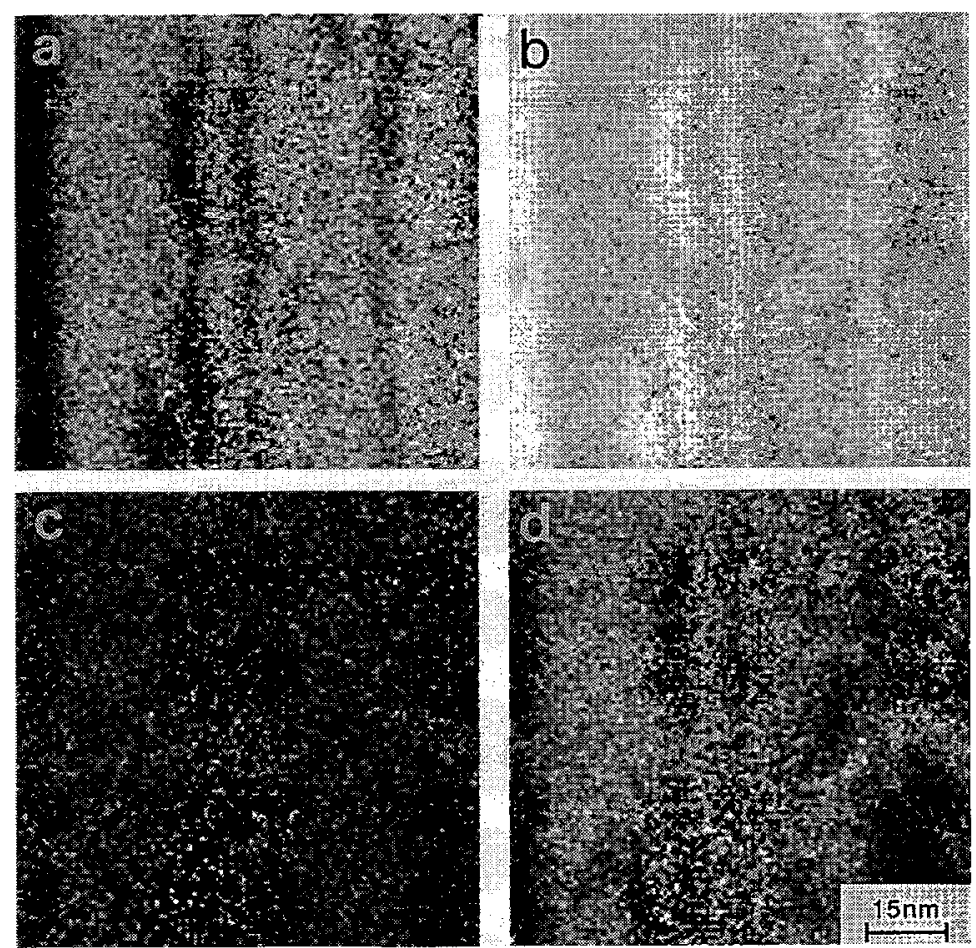

Fig. 3. X-ray maps across a dispersoid region revealing the interleaved phase morphology. (a) $\mathrm{Al} \mathrm{K}_{\alpha}$ peak. (b) $\mathrm{Ti} \mathrm{K}_{\alpha}$ peak. (c) $\vee \mathrm{K}_{\beta}$ peak. (d) $\mathrm{Fe} \mathrm{K}_{\alpha}$ peak.

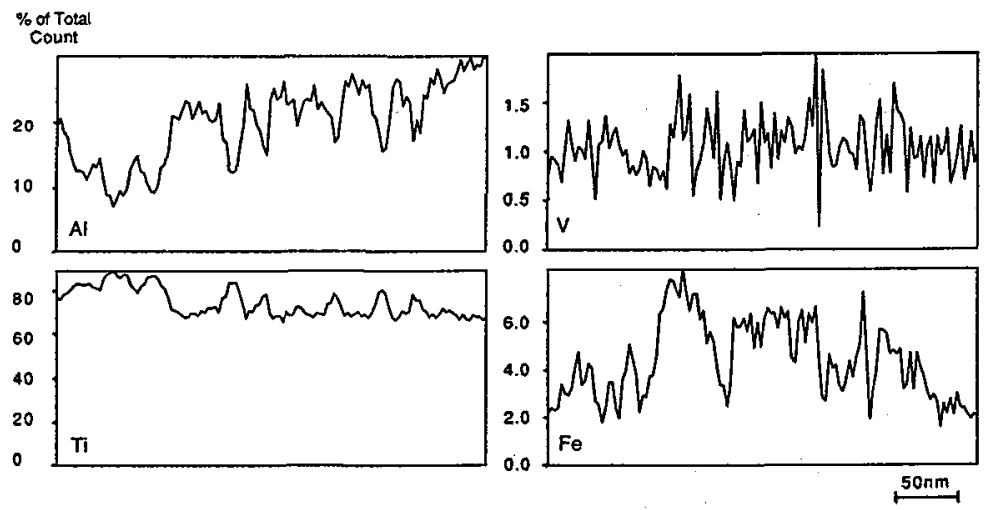

Fig. 4. $\mathrm{X}$-ray line scans across the same dispersoid region used for the $\mathrm{X}$-ray mapping. (a) $\mathrm{Al} \mathrm{K}_{\alpha}$ peak. (b) $\mathrm{Ti} \mathrm{K}_{\alpha}$ peak. (c) $V \mathrm{~K}_{\beta}$ peak. (d) $\mathrm{Fe} \mathrm{K}_{\alpha}$ peak.

\subsection{EDX Spot spectra}

Spot spectra were taken in order to clarify the identification of the phase interleaved with the boride plates identified by EELS. The results from the interleaving phase (D1) and boride plates(D2) are presented normalized to the total count and summarized in Table 1 alongside sample spot spectra of the bulk $\gamma, \alpha_{2}$ and $\beta$ phases. Because of the very fine scale of the interleaving plates there will be an overlap of the spectra from the adjacent phases, making only wide plates unambiguously identifyable.

The results show that it is $\beta$-phase (D1) with its characteristically high $\mathrm{Fe}$ content that is interleaved with the boride plates (D2). Of all the dispersoid regions so far considered $\gamma$ and $\alpha_{2}$ have not been found to interleave with the borides. The EDX spectra taken from the boride plates have 
characteristically more than $90 \%$ Ti counts i.e. the solubility of the $\mathrm{Al}, \mathrm{Fe}$ and $\mathrm{V}$ is minimal in these titanium boride plates. Those $\mathrm{Al}, \mathrm{Fe}$ and $\mathrm{V}$ counts registered are almost certainly due to stray scattering exciting $\mathrm{x}$-rays in surrounding grains.

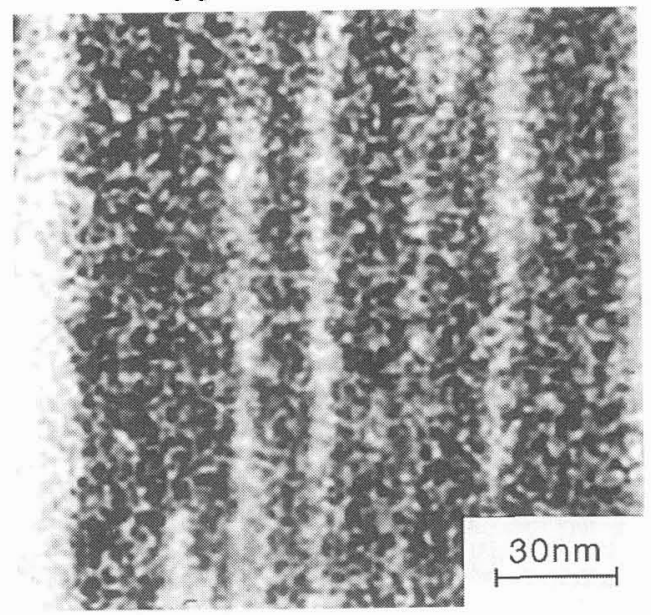

Fig. 5. Boron distribution across the interleaving dispersoid plates determined from EELS energy filtered images around the $188 \mathrm{eV}$ edge.

Table 1: STEM X-ray spot spectra results from the bulk $\gamma, \alpha_{2}$ and $\beta$ grains, and the two dispersoid phases D1 and D2 presented as percentage of total count for each of the $A 1 K_{\alpha}$,

$\mathrm{TiK}_{\alpha}, \mathrm{VK}_{\beta}$ and $\mathrm{FeK}_{\alpha} \mathrm{X}$-ray peaks, and $\mathrm{Al} / \mathrm{Ti}, \mathrm{Fe} / \mathrm{Al}$ and $\mathrm{Fe} / \mathrm{Ti}$ raw count ratios.

\begin{tabular}{|c|c|c|c|c|c|c|c|}
\hline Phase & $\begin{array}{l}\text { Al } K_{\alpha} \alpha \\
\text { Total }\end{array}$ & $\begin{array}{l}\text { Ti K } \alpha / \\
\text { Total }\end{array}$ & $\begin{array}{l}\mathrm{V} \mathrm{Kb} / \\
\text { Total }\end{array}$ & $\begin{array}{c}\mathrm{Fe} \mathrm{K}_{\alpha} \\
\text { Total }\end{array}$ & $\begin{array}{l}\operatorname{Al~K}_{\alpha} \\
\text { Ti } K_{\alpha}\end{array}$ & $\begin{array}{c}\mathrm{Fe} \mathrm{K}_{\alpha} \\
\mathrm{Al} \mathrm{K}_{\alpha}\end{array}$ & $\begin{array}{c}\text { Fe K } \alpha_{\alpha} \\
\operatorname{Ti~}_{\alpha}\end{array}$ \\
\hline$\gamma$ & 39.5 & 59.0 & 0.1 & 1.3 & 66.9 & 3.4 & 2.3 \\
\hline$\alpha_{2}$ & 27.2 & 72.0 & 0.1 & 0.7 & 37.8 & 2.5 & 0.9 \\
\hline$\beta$ & 24.6 & 65.6 & 0.5 & 9.3 & 37.4 & 37.8 & 14.1 \\
\hline $\mathrm{D}(\bar{B})$ & 212 & 717 & 01 & 66 & 207 & 310 & 02 \\
\hline $\mathrm{D} 2(\mathrm{~B})$ & $\frac{1.0}{11.6}$ & 85.0 & 0.4 & $\frac{0.0}{3.2}$ & $\frac{29.1}{11.6}$ & $\frac{31.0}{27.9}$ & $\frac{9.2}{3.4}$ \\
\hline
\end{tabular}

\section{DISCUSSION}

The addition of boron to a $\gamma-\alpha_{2}-\beta$ TiAl based alloy has led to the formation of dispersoids with a distinctive flake morphology. These flakes have been identified as consisting of interleaved $\beta$ and titanium boride plates, both with a very high aspect ratio reflecting the morphology of the dispersoids as a whole. The reason $\beta$-phase can be observed at room temperature is that the $\mathrm{B} 2 \mathrm{CsCl}$ structure is stabilized by $\mathrm{Fe}$ and $\mathrm{V}$ occupying the Al sublattice in the b.c.c. structure [7].

The $\beta$-phase and boride appear to have simultaneously nucleated from one another in the melt in order to achieve such an interleaved morphology. The plates are non-continuous along the length of the dispersoid, due to plates which have nucleated at different points across the flake impinging on one another. For binary systems, $\beta$ has been identified as being the primary phase in local equilibrium with the melt for Ti rich compounds with 40-49at.\%Al [9], and it is concluded here that $\beta$ is the primary phase for this TiAl (Fe-V-B) based alloy. The $\beta$ phase in the dispersoids has undergone the transformation $\beta$ (disordered) $\rightarrow \beta$ (ordered) rather than the transformation $\beta$ (disordered) $\rightarrow \alpha \rightarrow \alpha_{2}+\gamma$ $+\beta$ (ordered) since no $\gamma$ or $\alpha_{2}$ particles have been found interleaved with the boride. The dispersoids formed before or during the precipitation of the primary $\beta$ phase and primary $\gamma$ segregate since they delineate different lamellar transformation regions and also occur within primary $\gamma$ grains [2].

In the analysis of EELS spectra, there were no boron edges detectable in the bulk $\gamma, \alpha_{2}$ or $\beta$ phases or at their interfaces, indicating that there is only strong segregation of boron in these dispersoid regions where it is concentrated in the boride plates. The boride does not appear to dissolve a significant amount of $\mathrm{Al}, \mathrm{Fe}$ or $\mathrm{V}$ at room temperature, and $\mathrm{Fe}$ or $\mathrm{V}$ borides are less favourable than $\mathrm{Ti}$ borides. This differs from the case of $\mathrm{Ta}$ and $\mathrm{Nb}[10,11]$ where $\mathrm{TaB}$ or $\mathrm{NbB}$ can precipitate, or $\mathrm{Ta}$ or 
$\mathrm{Nb}$ substitute for $\mathrm{Ti}$ in the metal $\mathrm{TiB}$ sublattice. $\mathrm{B}$ is a poor substitutional solute and does not readily fill interstices in the $\beta$-phase due to its relatively large size with respect to Ti[12]. There is a high density of interfaces present in a very small area with this morphology, suggesting that there is little driving force for particle coarsening and possibly poor boron diffusion through the $\beta$-phase due to the very small interstices.

Considering titanium boride morphologies, a wide range have been previously identified in TiAl based alloys such as equiaxed particles, plates, flakes and needles [8]. When boron is added to binary alloys [1-3] the Ti / Al ratio partly determines the morphology of the titanium boride phase by determining the primary crystallization phases and phase transformations which occur from the melt to room temperature equilibrium. The quantity of boron added affects which particular boride phase is observed, most commonly $\mathrm{TiB}_{2}$, TiB (B27 structure), or TiB (metastable, Bf structure), which acquire different morphologies depending on the preferred crystal growth directions of that particular phase $[1,2]$. Extensive work by Hyman et al $[2]$ has led to the conclusion that a single-phase $\mathrm{TiB}_{2}$ flake-like morphology, as opposed to a blocky one occurs when the volume of boron added is <1at.\%. As the volume of boron increases then needles, plates and equiaxed particles are successively produced. The flake-like morphology is interpreted as a result of the constraints inflicted by a matrix growing concurrently with the boride[1]. In this alloy the flake morphology is a result of two intermingled phases growing concurrently. $\mathrm{TiB}_{2}$ is usually the primary boride phase for TiAl ratios expected for the Ti/Al ratio present in this alloy without the Fe or V doping. Clarification of the stoichiometry of the boride phase is in this alloy hampered in this alloy by the very fine scale of these borides making orientation difficult in addition to the problems of quantitative EELS.

The motivation for the inclusion of dispersoids in a TiAl microstructure has been grain refinement to improve high temperature workability[4] and effective creep reduction by dispersion hardening, constraining the plastic flow of matrix at high temperature[2]. Grain size in $\gamma / \alpha_{2}$ alloys decreases with increased volume of boride particulate[5] which has been suggested is due to the boride acting as nucleation sites for the primary $\beta / \alpha$ phases leading to more differently oriented $\alpha_{2} / \gamma$ domains at room $T$. In this alloy the boride plates do indeed act as nucleation sites for the $\beta$ phase, and once all the boron had precipitated, then larger $\beta$ grains grow producing the primary crystallization grains, and $\gamma$ segregates. Flake-like dispersoids may also be more effective as creep reinforcements than the same volume of boride distributed as equiaxed particles.

\section{CONCLUSIONS}

1. The boron distribution can be determined from EELS energy filtered images, and correlated with EDX results in order to identify the phases present.

2. Boron segregates to dispersoids formed before the $\beta \rightarrow \alpha \rightarrow \gamma+\alpha_{2}+\beta$ solid state transition.

3. The flake-like dispersoids have a complex structure of titanium boride and $\beta$-phase plates, interleaved on a nm scale.

4. Simultaneous nucleation of boride and $\beta$-phase occurs within the melt, the $\beta$-phase stabilized at room temperature in the bulk microstructure and dispersoids by $\mathrm{Fe}$ and $\mathrm{V}$.

\section{ACKNOWLEDGEMENTS}

The support of Ishikawajima-Harima Heavy Industries Ltd (IHI) by providing a research grant is gratefully acknowledged. B.J. Inkson would like to thank the SERC for funding.

\section{REFERENCES}

1. M.E. Hyman, C. McCullough, J.J. Valencia, C.G. Levi and R. Mehrabian, Metall. Trans. A 20A, 1847 (1989).

2. M.E. Hyman, C.McCullough, C.G. Levi and R. Mehrabian, Metall. Trans. A 22A, 1647 (1991).

3. M. De Graef, J.P.A. Löfvander, C. McCullough and C.G. Levi, Acta Metall. Mater. 40, 3395 (1992).

4. A. Szaruga, L. Rothenflue, R. Srinivasan and H.A. Lipsitt, Scripta Met. 26, 1565 (1992).

5. J.D. Bryant, L. Christodoulou and J.R. Maisano, Scripta Met. \& Mat. 24, 33 (1990).

6. Y.G. Nakagawa, S. Yokoshima and K. Matsuda, Mat. Sci. \& Eng. A153, 722 (1992).

7. B.J. Inkson, C.B. Boothroyd and C.J. Humphreys, Acta Met. in press (1993).

8. M.J. Blackburn and J.C. Williams, T.M.S.-A.I.M.E. 239, 287 (1967).

9. C. McCullough, J.J. Valencia, C.G. Levi and R. Mehrabian, Acta Met. 37, 5, 1321 (1989).

10. M. De Graef, J.P.A. Löfvander, and C.G. Levi, Acta Metall. Mater. 39, 2381 (1991).

11. J.J. Valencia, J.P.A. Löfvander, C. McCullough, C.G. Levi and R. Mehrabian, Mat. Sci. \& Eng., A144, 25, (1991).

12. S.H. Whang, J. of Mat. Sci., 21, 2224 (1986). 